\title{
The Effects of Road and Other Pavement Materials on Urban Heat Island (A Case Study of Port Harcourt City)
}

\author{
Elenwo Ephraim Ikechukwu \\ Department of Geography and Environmental Management, Faculty of Social Science, University of Port \\ Harcourt, Choba, Nigeria \\ Email: iyke2 elenwo@yahoo.com
}

Received 8 February 2015; accepted 10 April 2015; published 13 April 2015

Copyright (C) 2015 by author and Scientific Research Publishing Inc.

This work is licensed under the Creative Commons Attribution International License (CC BY). http://creativecommons.org/licenses/by/4.0/

(c) (i) Open Access

\begin{abstract}
Urban centers are consistently exhibiting higher temperature than its surrounding suburban rural areas. The large amount of heat generated from urban structures such as road materials and pavement materials and other anthropogenic heat sources are the main causes of Urban Heat Island (UHI). The sources of data for this research included primary and secondary sources. Other techniques employed for data collection were direct measurement and readings on the road and pavement materials. The research found out that, there was consistency in rising temperature at different time of the day by the different road and pavement materials. Asphalt has the greatest effect of increasing the urban temperature four degrees higher, followed by concrete, three degree rise in temperature, and earth (ordinary ground) by two degree rise and vegetation (grass) by one degree rise in temperature. The overall effect on the residents of the study area ranges from increase in hotness of the day; $44.6 \%$ respondents agrees; while $34.3 \%$ says it affects the ambient air quality of the area, and other effects such as increased ground level ozone, suffocation, sleeplessness and restlessness as a result of excessive high temperature especially at night are identified in this paper. The research recommends the review or redesigning of the entire Port Harcourt city Master Plan to make provision for creation of more green areas rather than pavements and concreted areas to reduce the effects of (UHI) and ultimately improve the comfort and living conditions of the people in a the garden city Port Harcourt.
\end{abstract}

\section{Keywords}

Effects, Road and Pavement Materials, Urban Heat Island, Residents, Port Harcourt 


\section{Introduction}

Since 1960 till date, for many complex and interrelated reasons cities in the developing world have experienced unprecedented growth Mabojunje [1]. The growth itself is self-perpetuating in that it continues to attract people, jobs, services, interests, and opportunities. Urban populations have increased at rates, which have had profound implication on the demand for housing and the provision of urban infrastructural facilities. As a result, in almost all developing countries, Nigeria inclusively, there has been an inability of authorities (government) to respond adequately to rapid urbanization and in particular to provide adequate basic services, a situation which is proving detrimental to the provisions of the basic needs and maintenance of healthy living for the people and the environment Mabojunje [1]. Environmental health conditions in many cities are severely threatened. An increasing proportion of urban housing is hurriedly built and cities that have experienced this rapid growth are largely unplanned and if the plans are there, they were never implemented. The rapid urbanization and industrialization of most cities today have resulted in several of the built up areas to be concreted alongside the roads with less open spaces left for greenery and play grounds. The consequences are total environmental deterioration occasioned by excessive urban heat island. Research has shown that urban places are warmer than surrounding rural environment and this phenomenon has given rises to the term, Urban Heat Island (UHI) which refers to the fact that the cities, especially the city centers or their down town sections consistently exhibit higher temperatures than surrounding rural areas [2]. As urban areas of the world develop, changes occur in their landscape, buildings, roads, and other infrastructural facilities which replace open spaces and vegetations. Surfaces that were once permeable and moist become impermeable and dry; these changes cause urban regions to become warmer than their out skirts or rural surroundings or fringes, forming an "island" of higher temperatures in the landscape. Heat islands occur on the surface and in the atmosphere, surface urban heat islands are typically present day and night, but tend to be strongest during the day when the sun is shining. In contrast atmospheric urban islands are often weak during the late morning and throughout the day and become more pronounced after sunset due to slow release of heat from infrastructures such as building materials, road materials and pavement materials etc. [3].

\subsection{Statement of the Problem}

In recent times, the petroleum industry has had a direct and national significant impact on the growth of Port Harcourt city both in the regional and national contest, the city has remained an important urban area because of its garden city status of greenery and planned environment. Movement of major multinationals oil companies to the city of Port Harcourt has accelerated the congestion of the city. The present situation has created immense pressure on the roads and other infrastructural facilities in the city. The situation is such that movement from one point of the city to another is very chaotic, frustrating and psychologically stressful especially on a typical sunning day. Cities can be several degrees warmer than the adjacent rural areas mainly because of the solar energy absorbed and stored by the built environment. This phenomenon is referred to as the Urban Heat Island (UHI) effect. Pavements, which typically comprise $30 \%$ - $45 \%$ of the land area in major cities, as in Port Harcourt, are a significant contributor to the UHI, due to their decreased ability to reflect incoming solar radiation and their increased thermal storage capacity.

During the summertime, elevated surface and air temperatures can have a number of undesirable health, environmental, and economic impacts, which are briefly described under: Health: Beyond causing increased human and ecosystem discomfort, UHI would exacerbate heat waves, which can lead to mortality. For instance, more than 700 deaths were attributed to excessive heat event conditions in Cook County, Illinois, U.S.A in 1995. Approximately 30,000 deaths occurred in Europe during a 2003 heat wave. Environmental: The UHI can worsen air quality by promoting ground-level ozone formation [4]. A Laboratory study in the United States estimated that the Los Angeles heat island can increase ground-level ozone levels by more than 10\% [5]. This has resulted in many agencies and organizations to develop mitigation strategies for the UHI as part of their air quality plans. Higher surface temperatures from pavements impair water quality by heating pavement runoff, causing thermal shock for aquatic life as well as impairing the ability to the growth of healthy urban forests. It is as a result of the foregoing that this research focuses on the effects of Road and pavement materials on the residents of Port Harcourt city Rivers State. The magnitude of the temperature difference depends on a variety of factors such as time of day, cloudiness, season etc.

\subsection{Study Objectives}

The research investigated the effects of urban heat island on the health of residents of Port Harcourt city. The 
objectives include;

1) To determine the significant change in temperature on a typical sunning day in Port Harcourt city.

2) To investigate the reactions of residents affected by the urban heat island in the city of Port Harcourt.

3) To investigate other environmental media that is affected by the urban heat island.

4) To proffer appropriate mitigation measures to stem the scourge of urban heat island in the city of Port Harcourt.

\section{Causes of Urban Heat Island (UHI)}

There are several causes of UHI. The main cause of the urban heat island is modification of the land surface by urban development, waste heat generated by energy usage is a secondary contributor. The principal reason for the night time warming is that building block surface usually radiate heat into the relative cold night sky. Two other reasons are changes in the thermal properties of surface materials and lack of vapor-transpiration in urban areas. Materials commonly used in urban areas, such as concrete and asphalt, have significantly different thermal bulk properties (including heat capacity and thermal conductive) and surface radioactivity properties (albedo and emissivity) than the surrounding rural areas. This causes a change in the energy balance of the urban area, often leading to higher temperature than the surrounding areas. The energy balance is also affected by the lack of vegetation in urban areas, which inhibits cooling by evapotranspiration [6].

Other causes of a UHI are due to geometric effects. The tall buildings within many urban areas provide multiple surfaces for the reflection and absorption of sun light, increasing the efficiency with which urban areas are heated. This is called the "urban canyon effect". Another effect of buildings is the blocking of wind, which also inhibits cooling by convection. Waste heat from automobiles, air conditioning, industry, and other sources also contributes to the UHI. High levels of pollution in urban areas can also increase the UHI, as many forms of pollution change the radioactive properties of the atmosphere some cities exhibit a heat island effect which is largest at night seasonally. UHI shows up both summer and winter [6]. The typical temperature difference IS several degrees between the center of the city and surrounding fields. The difference in temperature between an inner city and its surrounding suburbs is frequently mentioned in weather reports: e.g. $32^{\circ} \mathrm{C}$ downtown, $26^{\circ} \mathrm{C}$ in the suburbs. The colour black absorbs significantly more electromagnetic radiation, and causes the surfaces of roads and highways to heat up substantially.

\subsection{Impacts on Weather and Climate}

Aside from the effect on temperature, UHI can produce secondary effects on local meteorology, including the altering of local wind patterns, the development of clouds and fog, the difference in humidity, and the rates of precipitation. The extra heat provided by UHI leads to greater upward motion, which can induce additional shower and thunderstorm activity. Rainfall rates downwind of cities are increased between $16 \%$ and $48 \%$. Partly as a result of this warming, monthly rainfall is about $28 \%$ greater between 20 miles (32 km) to 40 miles (64 km) downwind of cities, compared with up wind some cities show a total precipitation increase of $51 \%$ [7]. According to [8], his research suggests that metropolitan areas are less susceptible to weak tornadoes due to the turbulent mixing caused by the warmth of the urban heat island. Other research findings suggests that using satellite images, it was observed that city climates have a noticeable influence on plant growing seasons up to 10 kilometers (6 miles) away from a city's edges [5]. Growing seasons in 7 cities in North East Nigeria were about 15 day's longer in urban areas compared to rural areas outside of a city's influence [9].

\subsection{Health Effects}

UHIs have the potential to directly influence the health and welfare of urban residents. Within the United States alone, an average of 1000 people dies each year due to extreme heat [10]. UHI are characterized by increased temperature, they can potentially with the maximum temperature an effect that is exacerbated by the UHI [11]. The night time effect of UHI can be particularly harmful during a heat wave, as it deprives urban residents of the cool relief found in rural areas during the night.

Research in the United States suggests that the relationship between extreme temperature and mortality varies by location [12]. Heat is more likely to increase the risk of mortality in cities at mid-latitudes and high latitudes with significant annual temperature variation [13]. For example, when Chicago and New York experience un- 
usually hot summertime temperatures elevated level of illness and death are predicted [14]. In contrast, parts of the country that is mild to heat year round have a lower public health risk from excessive heat [15]. Research shows that resident of Southern cities tend to be acclimated to hot weather conditions and therefore less vulnerable to heat related death [16]. Increased temperature on sunny day's help lead to the formation of low-level ozone from volatile organic compounds and nitrous oxides which already exist in the Air [17]. As urban heat island lead to increased temperature with cities, they contribute to worsened air quality. The higher temperatures in urban heat islands increases air conditioning needs and raises pollution levels [18]. Urban heat island are not only uncomfortable hot, they are also smoggier. Smog is created by photochemical reaction of pollutants in the air, these reactions are more likely to occur and intensify at higher temperature in urban areas [19]. For example, for every degree $21^{\circ} \mathrm{C}$, the incidence smog is increases by $3 \%$. Higher ambient temperature in heat island also increases air conditioning energy use. As power plants burn more fossil fuels, they increase both pollution level and energy cost. The impact of these pollution levels is seen in smog. The formation of smog is highly sensitive to temperatures, the higher the temperature, the higher the formation of and hence the concentration of smog. In Los Angeles at temperature below $21^{\circ} \mathrm{C}$ the concentration of smog (measured as Ozone) is below the national standard. At a temperature of about $35^{\circ} \mathrm{C}$ all days are smoggy. Cooling the city by about $5^{\circ} \mathrm{C}$ would have a dramatic impact on smog concentration link to high temperature. UHI also impair water quality [20]. Hot pavement and rooftop surfaces transfer their excess heart to storm water, which then drains into storm sewers and raises water temperature as it is released into streams, rivers, ponds and lake's rapid temperature changes can be stressful to aquatic ecosystem [21].

\section{Materials and Methods}

\subsection{Sources of Data/Instruments for Data Collection}

The sources of data for this research included primary and secondary sources. Data obtained from the field survey using the questionnaire instrument constituted the primary source of data. Other techniques employed for data collection was direct measurement and reading on the road materials and pavement materials, the earth (ordinary ground), and on the vegetation (grass) on the intervals of two hours (six times) daily for three days on the sample locations. The instruments used to collect data on the three different locations were as follows:

1) Liquid in glass thermometer (dry bulb thermometer)

2) Wet and dry bulb hygrometer

These instruments were obtained from the University of Port Harcourt, Physics department Material Science laboratory. The instrument used for measuring the temperature of road materials, pavement materials, Earth (ordinary ground) and vegetation (Grass) made use of the physical property that changes with temperature, which is increase or expansion in volume of a liquid when it is heated. Furthermore, a total of 300 copies of questionnaires of dichotomous nature, were administered face to face to the respondents, that is residents of Port Harcourt. This was done to elicit their perception of the urban heat island and the attendant effects on their health and the environment.

\subsubsection{Liquid-in-Glass Thermometer}

This instrument has two reference temperatures called fixed points or fixed temperature. The higher temperature is called the upper fixed point and the lower temperature is called the lower fixed point. The scale of the thermometer is the Celsius scale in which the upper fixed point is chosen $100^{\circ} \mathrm{C}$ and lower fixed point is $0^{\circ} \mathrm{C}$. This is also called the centigrade scale. The interval between the upper and the lower fixed point is called fundamental intervals. This interval is divided into one hundred equal parts and each part defines one degree on the scale. The wet and dry bulb hygrometer used for measuring of relative humidity consists of two thermometers, the wet bulb thermometer and the dry bulb thermometer. The wet bulb thermometer has its bulb wrapped in a piece of moist cloth dipped into a water pot. The dry bulb shows the temperature of dry air, while the wet bulb records a lower temperature because evaporation of water from cloth cools it. If there is much water in the atmosphere, i.e. fithe relative humidity is high water from the wet cloth evaporates only very slowly. The difference in the temperatures recorded by the two thermometers will therefore be small. When the humidity is low, water evaporates at a fast rate from the wet cloth. The wet bulb will record a low temperature making the difference between the two temperatures high. The lower the humidity the lower the temperature of the wet bulb thermometer relative to the dry bulb thermometer. The difference between the readings of wet and dry bulb thermometer is a measure of the 
relative humidity.

\subsubsection{Temperature}

The liquid-in-glass thermometer was brought in close contact with the urban corridors road materials, pavement materials, earth (ordinary ground) and vegetation (Grass) respectively, the temperature was measured and the reading of the thermometer taken at that time. After an interval of two hours each for six different times the reading of the thermometer was also taken and the temperature variation noted for three consecutive days.

\subsubsection{Relative Humidity}

The hygrometer (Wet and dry bulb thermometer) was also brought in close contact with their urban corridors: road materials, pavement materials, Earth (ordinary ground) and vegetation (Grass) respectively, the relative humidity was measured and reading of the hygrometer taken at that time. After an interval of two hours each for six different times the reading of the humidity variation noted for three consecutive days. And all the data collected for both temperature and relative humidity on the eight different locations for the seven days were tabulated and analyzed.

\subsection{Technique for the Determination of Sample Size}

The sample for the study was drawn using the stratified random sampling method. The first stage was the listing of communities that make up the neighbourhood thereafter, the selection of the residential neighbourhoods. One neighbourhood was picked from each stratum. The neighbourhood data was adapted from [22]. At the end of the sampling, three strata emerged. For the high density ${ }^{*} \mathrm{H} 1$ was picked; and ${ }^{* *} \mathrm{M} 6$ was picked for medium density, while ${ }^{* * *} \mathrm{~L} 15$ was picked for low density areas.

The sample size was determined using the formula, for the purposes of questionnaire administration [23]. The equation is written as;

$$
N=\frac{N}{1+N\left(e^{2}\right)}
$$

where;

$$
\begin{aligned}
& n=\text { sample size } \\
& N=\text { total population } \\
& 1=\text { constant } \\
& e=\text { level if significance }(0.05)^{2}
\end{aligned}
$$

And the house hold sizes derived from the [24] and the [25]. Furthermore, a 5\% house hold size in the study area was determined, thus a total of $300 \mathrm{H} / \mathrm{H}$ (households) were sampled amongst the selected residential neighbourhoods, (see Table 1).

\section{Results}

The measurements were taken for three days on the three different locations that make up the sample location for six different times at an interval of two hours each. The data is tabulated as follows (Tables 2-11):

Tables 7-11 showed the measurement of the different temperature readings from the three locations; measuring the temperature of road materials, pavement materials, Earth (ordinary ground) and vegetation (Grass). The readings showed that there is consistency in rising (increase) in temperature and falling (decrease) in temperature for the different types of road materials and pavement materials for the three different locations. The rise in temperature is further corroborated as shown in the charts, in Figures 1-4.

\subsection{Data Analysis (Questionnaires)}

Table 12 and Table 13 shows the distance of buildings and properties within Port Harcourt city their distances from road and pavement materials and possible effects on them and the environment. The former shows that about $51.3 \%$ and $40.0 \%$ fall within 10 to 20 meters away from road and pavement materials. This shows that the impact of the roads and pavement materials are actually felt by the residents. The impacts are stated in Table 13 above. The effects range from increase in hotness of the day $44.6 \%$ agrees, while $34.3 \%$ says it affects the am- 
Table 1. List of selected residential neighbourhoods. (sample locations).

\begin{tabular}{ccccc}
\hline S/N & Number picked/codes & Stratum & Density & Nieghbourhoods \\
\hline 1 & H1 & I & ${ }^{*}$ HD & Mile I Diobu \\
2 & M6 & 11 & ${ }^{* *}$ MD & Rumuomasi \\
3 & L15 & 111 & ${ }^{* * *}$ LD & Old GRA
\end{tabular}

${ }^{*}$ HD: high density, ${ }^{* *}$ MD: medium density, ${ }^{* * *}$ LD: low density. (Field Survey).

Table 2. Temperature and relative humidity for stratum 1 high density neighbourhood ( $\left.{ }^{*} \mathrm{HD}\right)$ mile one diobu.

\begin{tabular}{ccccccccc}
\hline & \multicolumn{9}{c}{ Road and Pavement Materials } & Earth, i.e. (Ordinary Ground) & Vegetation, i.e. (Grass) \\
\cline { 2 - 9 } Time & \multicolumn{2}{c}{ Asphalt } & \multicolumn{2}{c}{ Concrete } \\
\cline { 2 - 9 } & TEMP $\left({ }^{\circ} \mathrm{C}\right)$ & R.H (\%) & TEMP $\left({ }^{\circ} \mathrm{C}\right)$ & R.H $(\%)$ & TEMP $\left({ }^{\circ} \mathrm{C}\right)$ & R.H $(\%)$ & TEMP $\left({ }^{\circ} \mathrm{C}\right)$ & R.H $(\%)$ \\
\hline 8.00 a.m & 21 & 80 & 21 & 80 & 21 & 80 & 21 & 80 \\
10.00 a.m & 25 & 65 & 24 & 65 & 23 & 65 & 22 & 65 \\
12.00 noon & 29 & 60 & 27 & 50 & 25 & 50 & 23 & 50 \\
2.00 p.m & 33 & 35 & 30 & 35 & 27 & 35 & 24 & 35 \\
4.00 p.m & 29 & 50 & 27 & 50 & 25 & 50 & 23 & 50 \\
6.00 p.m & 25 & 65 & 24 & 65 & 23 & 65 & 22 & 65 \\
\hline
\end{tabular}

Table 3. Temperature and relative humidity for stratum 11 medium density neighbourhood ( $\left.{ }^{* *} \mathrm{MD}\right)$ rumuomasi.

\begin{tabular}{|c|c|c|c|c|c|c|c|c|}
\hline \multirow{3}{*}{ Time } & \multicolumn{4}{|c|}{ Road and Pavement Materials } & \multicolumn{2}{|c|}{ Earth, i.e. (Ordinary Ground) } & \multicolumn{2}{|c|}{ Vegetation, i.e. (Grass) } \\
\hline & \multicolumn{2}{|c|}{ Asphalt } & \multicolumn{2}{|c|}{ Concrete } & \multirow[b]{2}{*}{$\operatorname{TEMP}\left({ }^{\circ} \mathrm{C}\right)$} & \multirow[b]{2}{*}{ R.H (\%) } & \multirow[b]{2}{*}{$\operatorname{TEMP}\left({ }^{\circ} \mathrm{C}\right)$} & \multirow[b]{2}{*}{ R.H (\%) } \\
\hline & TEMP $\left({ }^{\circ} \mathrm{C}\right)$ & R.H (\%) & $\operatorname{TEMP}\left({ }^{\circ} \mathrm{C}\right)$ & R.H (\%) & & & & \\
\hline 8.00 a.m & 20 & 85 & 20 & 85 & 20 & 85 & 20 & 85 \\
\hline 10.00 a.m & 24 & 70 & 23 & 70 & 22 & 70 & 21 & 70 \\
\hline 12.00 noon & 28 & 55 & 26 & 55 & 24 & 55 & 22 & 55 \\
\hline 2.00 p.m & 32 & 40 & 29 & 40 & 26 & 40 & 23 & 40 \\
\hline 4.00 p.m & 28 & 55 & 26 & 55 & 24 & 55 & 22 & 55 \\
\hline 6.00 p.m & 24 & 70 & 23 & 70 & 22 & 70 & 21 & 70 \\
\hline
\end{tabular}

Table 4. Temperature and relative humidity for stratum 111 low density neighbourhood $\left({ }^{* * *}\right.$ LD) old GRA.

\begin{tabular}{ccccccccc}
\hline & \multicolumn{3}{c}{ Road and Pavement Materials } & Earth, i.e. (Ordinary Ground) & Vegetation, i.e. (Grass) \\
\cline { 2 - 8 } Time & \multicolumn{2}{c}{ Asphalt } & \multicolumn{2}{c}{ Concrete } \\
\cline { 2 - 9 } & TEMP $\left({ }^{\circ} \mathrm{C}\right)$ & R.H $(\%)$ & TEMP $\left({ }^{\circ} \mathrm{C}\right)$ & R.H $(\%)$ & TEMP $\left({ }^{\circ} \mathrm{C}\right)$ & R.H (\%) & TEMP $\left({ }^{\circ} \mathrm{C}\right)$ & R.H $(\%)$ \\
\hline 8.00 a.m & 19 & 90 & 19 & 90 & 19 & 90 & 19 & 90 \\
10.00 a.m & 23 & 75 & 22 & 75 & 21 & 75 & 20 & 75 \\
12.00 noon & 27 & 60 & 25 & 60 & 23 & 60 & 21 & 60 \\
2.00 p.m & 31 & 45 & 28 & 45 & 25 & 45 & 22 & 45 \\
4.00 p.m & 27 & 60 & 25 & 60 & 23 & 60 & 21 & 60 \\
6.00 p.m & 23 & 75 & 22 & 75 & 21 & 75 & 20 & 75 \\
\hline
\end{tabular}


Table 5. Temperature and relative humidity for asphalt $\left({ }^{*} \mathrm{HD},{ }^{* *} \mathrm{MD},{ }^{* * *} \mathrm{LD}\right)$.

\begin{tabular}{|c|c|c|c|c|c|c|}
\hline \multirow{2}{*}{ Time } & \multicolumn{3}{|c|}{ Location Temperature $\left({ }^{\circ} \mathrm{C}\right)$} & \multicolumn{3}{|c|}{ Location Relative Humidity } \\
\hline & Mile 1 Diobu ${ }^{*} \mathrm{HD}$ & $\begin{array}{l}\text { Old GRA } \\
{ }_{* * * *} \mathrm{LD}\end{array}$ & $\begin{array}{l}\text { Rumuomasi } \\
{ }_{* * *} \mathrm{MD}\end{array}$ & $\begin{array}{c}\text { Mile } 1 \\
\text { Diobu *HD }\end{array}$ & $\begin{array}{l}\text { Old GRA } \\
{ }^{* * *} \text { LD }\end{array}$ & $\begin{array}{l}\text { Rumuomasi } \\
{ }^{* *} \mathrm{MD}\end{array}$ \\
\hline 8.00 a.m & 21 & 20 & 19 & 80 & 85 & 90 \\
\hline 10.00 a.m & 25 & 24 & 23 & 65 & 70 & 75 \\
\hline 12.00 noon & 29 & 28 & 27 & 50 & 55 & 60 \\
\hline 2.00 p.m & 33 & 32 & 31 & 35 & 40 & 45 \\
\hline 4.00 p.m & 29 & 28 & 27 & 50 & 55 & 60 \\
\hline 6.00 p.m & 25 & 24 & 23 & 65 & 70 & 75 \\
\hline
\end{tabular}

Table 6. Temperature and Relative humidity for concrete ( $\left.{ }^{*} \mathrm{HD},{ }^{* *} \mathrm{MD},{ }^{* * *} \mathrm{LD}\right)$.

\begin{tabular}{|c|c|c|c|c|c|c|}
\hline \multirow{2}{*}{ Time } & \multicolumn{3}{|c|}{ Location Temperature $\left({ }^{\circ} \mathrm{C}\right)$} & \multicolumn{3}{|c|}{ Location Relative Humidity } \\
\hline & Mile 1 Diobu & Old GRA & Rumuomasi & Mile I Diobu & Old GRA & Rumuomasi \\
\hline 8.00 a.m & 21 & 20 & 19 & 80 & 85 & 90 \\
\hline 10.00 a.m & 24 & 23 & 22 & 65 & 70 & 75 \\
\hline 12.00 noon & 27 & 26 & 25 & 50 & 55 & 60 \\
\hline 2.00 p.m & 30 & 29 & 28 & 35 & 40 & 45 \\
\hline 4.00 p.m & 27 & 26 & 25 & 50 & 55 & 60 \\
\hline 6.00 p.m & 24 & 23 & 22 & 65 & 70 & 75 \\
\hline
\end{tabular}

Table 7. Temperature and relative humidity for earth (ordinary ground) in the three locations.

\begin{tabular}{|c|c|c|c|c|c|c|}
\hline \multirow{2}{*}{ Time } & \multicolumn{3}{|c|}{ Location Temperature $\left({ }^{\circ} \mathrm{C}\right)$} & \multicolumn{3}{|c|}{ Location Relative Humidity } \\
\hline & Mile 1 Diobu & Old GRA & Rumuomasi & Mile 1 Diobu & Old GRA & Rumuomasi \\
\hline 8.00 a.m & 21 & 20 & 19 & 80 & 85 & 90 \\
\hline 10.00 a.m & 23 & 22 & 21 & 65 & 70 & 75 \\
\hline 12.00 noon & 25 & 24 & 23 & 50 & 55 & 60 \\
\hline 2.00 p.m & 27 & 26 & 25 & 35 & 40 & 45 \\
\hline 4.00 p.m & 25 & 24 & 23 & 50 & 55 & 60 \\
\hline 6.00 p.m & 23 & 22 & 21 & 65 & 70 & 75 \\
\hline
\end{tabular}

Table 8. Temperature and relative humidity for vegetation (grass) in the three locations.

\begin{tabular}{|c|c|c|c|c|c|c|}
\hline \multirow{2}{*}{ Time } & \multicolumn{3}{|c|}{ Location Temperature $\left({ }^{\circ} \mathrm{C}\right)$} & \multicolumn{3}{|c|}{ Location Relative Humidity } \\
\hline & Mile One Diobu & Old GRA & Rumuomasi & Mile 1 Diobu & Old GRA & Rumuomasi \\
\hline 8.00 a.m & 21 & 20 & 19 & 80 & 85 & 90 \\
\hline 10.00 a.m & 22 & 21 & 20 & 65 & 70 & 75 \\
\hline 12.00 noon & 23 & 22 & 21 & 50 & 55 & 60 \\
\hline 2.00 p.m & 24 & 23 & 22 & 35 & 40 & 45 \\
\hline 4.00 p.m & 23 & 22 & 21 & 50 & 55 & 60 \\
\hline 6.00 p.m & 22 & 21 & 20 & 65 & 70 & 75 \\
\hline
\end{tabular}


Table 9. Temperature for stratum 1 *HD (Mile 1 Diobu).

\begin{tabular}{ccccc}
\hline \multirow{2}{*}{ Time } & \multicolumn{4}{c}{ Temperature for Road and Pavement Materials in $\left({ }^{\circ} \mathrm{C}\right)$} \\
\cline { 2 - 5 } & Asphalt & Concrete & Earth, i.e. (Ordinary Ground) & Vegetation, i.e. (Grass) \\
\hline 8.00 a.m & 21 & 21 & 21 & 21 \\
10.00 a.m & 25 & 24 & 23 & 22 \\
12.00 noon & 29 & 27 & 25 & 23 \\
2.00 p.m & 33 & 27 & 27 & 24 \\
4.00 p.m & 29 & 24 & 23 & 22 \\
6.00 p.m & 25 & &
\end{tabular}

Table 10. Temperature for stratum $11^{* *} \mathrm{MD}$ (Rumuomasi).

\begin{tabular}{ccccc}
\hline \multirow{2}{*}{ Time } & \multicolumn{4}{c}{ Temperature for Road and Pavement Materials in $\left({ }^{\circ} \mathrm{C}\right)$} \\
\cline { 2 - 5 } & Asphalt & Concrete & Earth, i.e. (Ordinary Ground) & Vegetation, i.e. (Grass) \\
\hline 8.00 a.m & 20 & 20 & 20 & 20 \\
10.00 a.m & 24 & 23 & 22 & 21 \\
12.00 noon & 28 & 26 & 24 & 22 \\
2.00 p.m & 32 & 29 & 26 & 22 \\
4.00 p.m & 28 & 26 & 24 & 21 \\
6.00 p.m & 24 & 23 & 22 & 22 \\
\hline
\end{tabular}

Table 11. Temperature for stratum $111{ }^{* * *}$ LD (Old GRA).

\begin{tabular}{ccccc}
\hline \multirow{2}{*}{ Time } & \multicolumn{5}{c}{ Temperature for Road and Pavement Materials in $\left({ }^{\circ} \mathrm{C}\right)$} \\
\cline { 2 - 5 } & Asphalt & Concrete & Earth, i.e. (Ordinary Ground) & Vegetation, i.e. (Grass) \\
\hline 8.00 a.m & 19 & 19 & 19 & 19 \\
10.00 a.m & 23 & 22 & 21 & 20 \\
12.00 noon & 27 & 25 & 23 & 21 \\
2.00 p.m & 31 & 28 & 25 & 22 \\
4.00 p.m & 27 & 25 & 23 & 20 \\
6.00 p.m & 23 & 22 & 21 & 22 \\
\hline
\end{tabular}

Table 12. Distance of building to road/pavements.

\begin{tabular}{cccc}
\hline & & Frequency & Percent \\
\hline & Less than 10 meters & 154 & 51.3 \\
& less than 20 meters away & 120 & 40.0 \\
Valid & 30 meters away & 16 & 5.3 \\
& 40 meters away & 10 & 3.3 \\
& 50 meters away & 00 & 0.0 \\
Total & 300 & 100.0
\end{tabular}


Table 13. Effects of urban heat island on respondents.

\begin{tabular}{cccc}
\hline & Frequency & Percent \\
\hline Increase heat level (temp. rise) & 134 & 44.6 \\
Poor ambient air quality & 103 & 34.3 \\
Valid & Impair water quality & 24 & 8.0 \\
& Thermal heat shock on aquatic life & 26 & 8.6 \\
Increased ground level ozone & 13 & 4.3 \\
Total & 300 & 100.0 \\
\hline
\end{tabular}

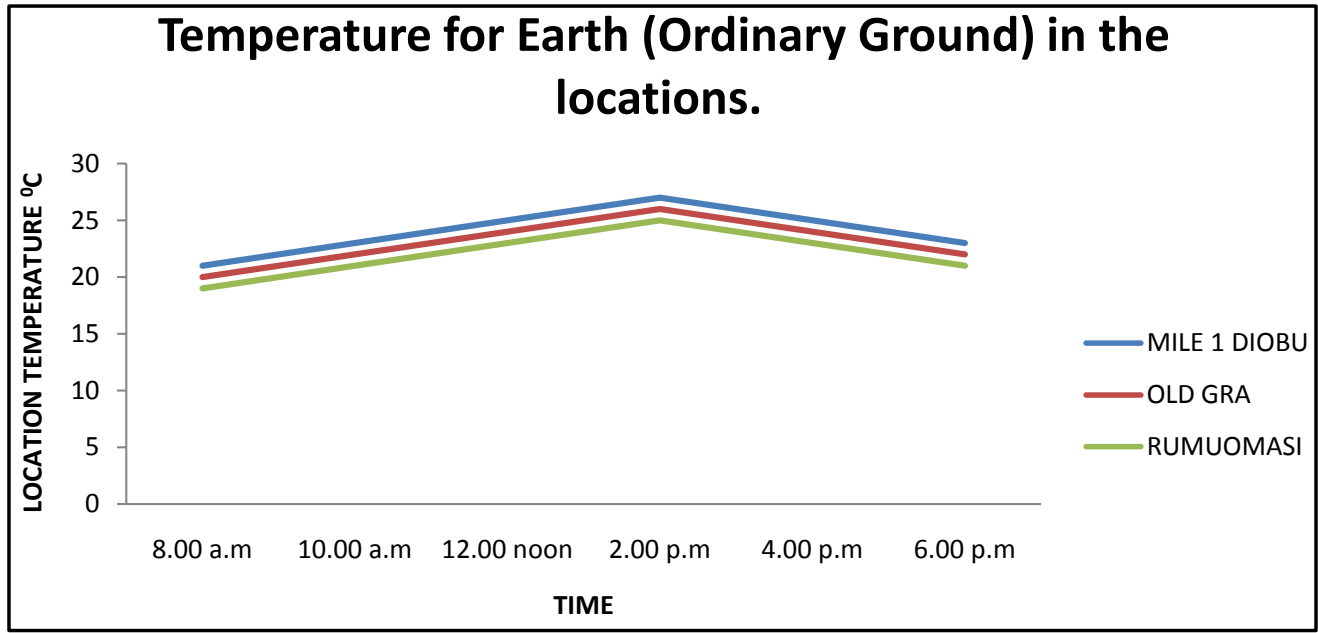

Figure 1. Temperature for earth (Ordinary Ground) in the locations.

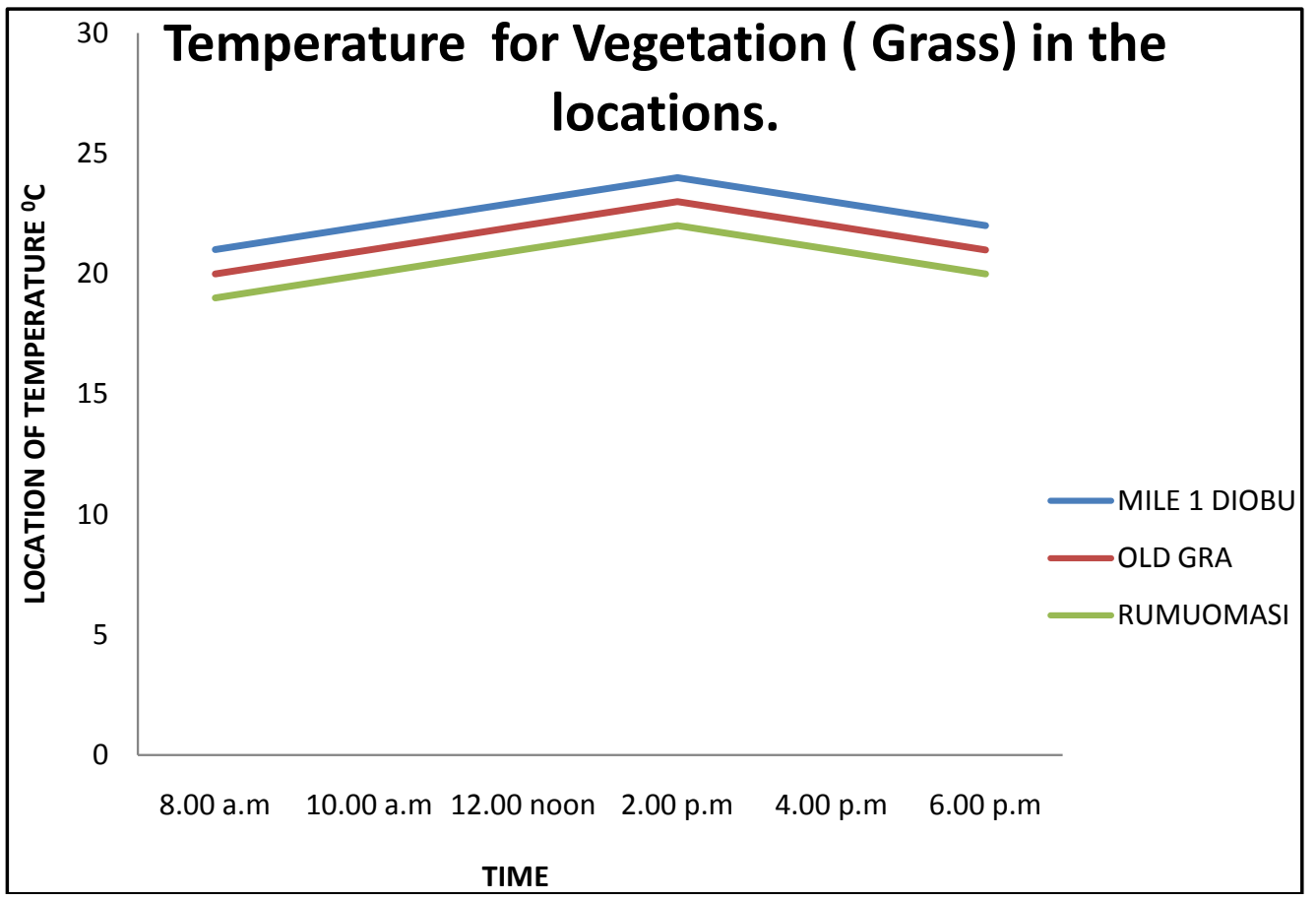

Figure 2. Temperature for vegetation (Grass) in the locations. 


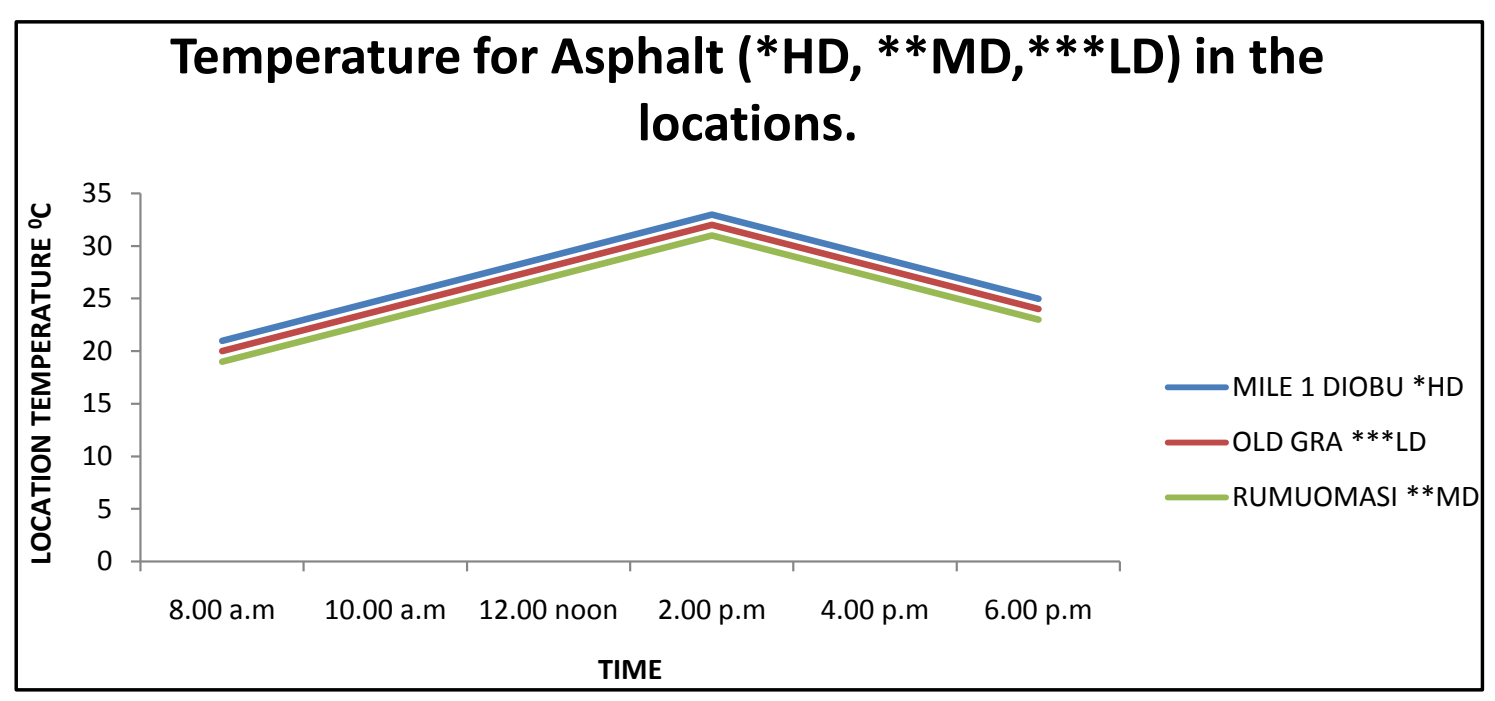

Figure 3. Temperature for asphalt $\left({ }^{*} \mathrm{HD},{ }^{* *} \mathrm{MD},{ }^{* * *} \mathrm{LD}\right)$ in the locations.

\section{Temperature for Concrete $\left({ }^{*} \mathrm{HD},{ }^{* *} \mathrm{MD}, * * * \mathrm{LD}\right)$ in the locations.}

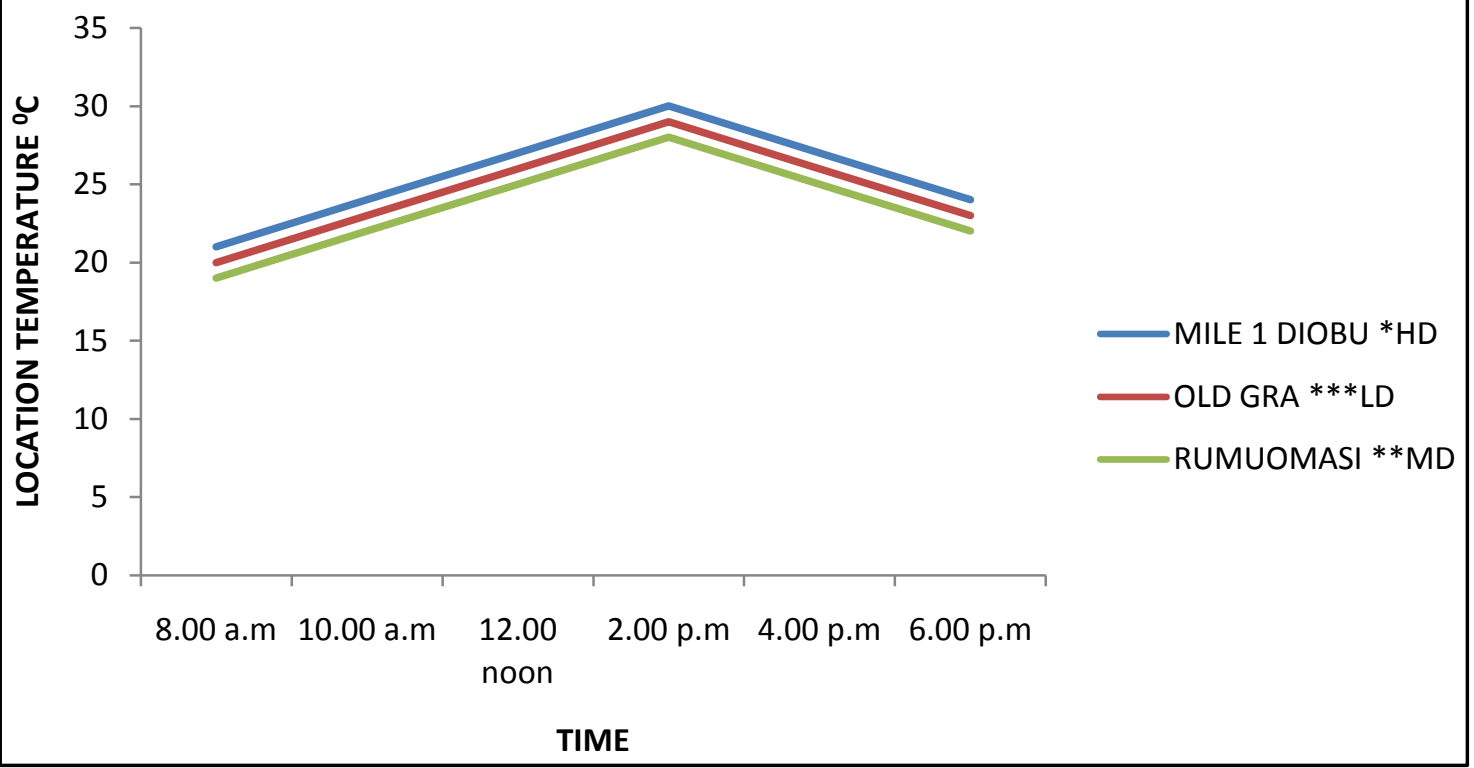

Figure 4. Temperature for concrete $\left({ }^{*} \mathrm{HD},{ }^{* *} \mathrm{MD},{ }^{* * *} \mathrm{LD}\right)$ in the locations.

bient air quality of the area, and other effects respectively.

Tables 13-15: shows the Rating of locations' Pleasure/Displeasure with effect of urban Heat Island. This was an important aspect of the group discussion with the respondents in the target population. The rating scale was as follows:

1). Very displeased

2). Somewhat displeased

3). Neither pleased nor displeased

4). Somewhat pleased

5). Very pleased 
Table 14. Respondents’ rating of pleasure and displeasure with (uhi) (percentage distribution).

\begin{tabular}{cccc}
\hline Location & Mile 1 Diobu & Rumuomasi & Old GRA \\
Attitude & & & 42.9 \\
Very Displeased & 63.0 & 69.6 & 13.1 \\
Somewhat Displeased & 29.6 & 0 & 0 \\
Neither Pleased Nor Displeased & 7.4 & 0 & 23.7 \\
Somewhat Pleased & 0 & 0 & 20.3 \\
Very Pleased & 0 & 30.4 & 100.0 \\
Total & 100.0 & 100.0 & \\
\hline
\end{tabular}

Table 15. Reasons for pleasure with (UHI).

\begin{tabular}{|c|c|c|}
\hline S/No & Community & Reasons for Pleasure \\
\hline 1. & Mile 1 Diobu & - Increased Heat wave and health Hazards. \\
\hline 2. & Rumuomasi & - $\quad$ Poor ambient air quality at night \\
\hline 3. & Old GRA & $\begin{array}{l}\text { - Feel such impact as a result of increased pavements } \\
\text { and removal of trees. }\end{array}$ \\
\hline
\end{tabular}

The results of the ratings, as well as the reasons for such ratings are shown in Table 13, and Table 15. From the ratings, in general, two out of the three locations tended to be more displeased than pleased with UHI. The reasons for this kind of situation are summarized in Table 15 and Table 16 respectively.

\subsection{Discussion of Findings}

Road materials and pavement materials has a significant effects on surface temperature, which subsequently influences ambient temperature. This can be seen from the data in the tables for temperature and relative humidity for the three different locations. In Table 5 the temperature for asphalt for the three different locations at respective relative humidity increased by four degree rise in temperature $\left(4^{\circ} \mathrm{C}\right)$ starting from the time 8.00 a.m to 2.00 p.m and decreased by four degree, i.e. ( drop in temperature $\left(4^{\circ} \mathrm{C}\right)$ from the time 2.00 p.m to $6.00 \mathrm{pm}$ at an interval of two hours each respectively. In Table 6 the temperature for concrete for the three different locations at respective relative humidity increased by three degree rise in temperature $\left(3^{\circ} \mathrm{C}\right)$ starting from the time 8.00 a.m to 2.00 p.m and decreased by three degree (drop in temperature $\left(3^{\circ} \mathrm{C}\right.$ ) from the time 2.00 p.m to 6.00 p.m at an interval of two hours each respectively.

In Table 7 the temperature for earth (ordinary ground) for the three different locations at respective relative humidity increased by one degree rise in temperature $\left(1^{\circ} \mathrm{C}\right)$ starting from the time 8.00 a.m to 2.00 p.m and decreased by one degree (drop in temperature $\left(1^{\circ} \mathrm{C}\right)$ from the time 2.00 p.m to 6.00 p.m at an interval of two hours each respectively. In Table 8 the temperature for vegetation (grass) for the three different location at respective relative humidity increased by $\left(2^{\circ} \mathrm{C}\right)$ starting from the time 8.00 a.m to $2.00 \mathrm{p} . \mathrm{m}$ and decreased by two degree drop in temperature $\left(2^{\circ} \mathrm{C}\right)$ from the time 2.00 p.m to 2.00 p.m at an interval of two hours each respectively. Similarly, from the Tables 9-11, it can be seen that there is consistency in rising (increase) in temperature and falling (decrease) in temperature for the different types of road materials and pavement materials for the three different locations.

The graphical representation for temperature in degree centigrade and time in hours, for the data obtained for the different road Materials and Pavement Materials (Asphalt, concrete, vegetation (grass) and earth (ordinary ground) are plotted as shown in Figures 1-4 respectively. The findings further reveal that urban places are warmer than the surrounding rural environments which confirm that heat island effect is real and not a myth.

In Table 9 the temperature for Mile 1 Diobu on the road and the different road pavements materials showed that asphalt has heat island (HI) greatest effect that increases the urban heat by four degree rise in temperature followed by concrete area by three degree rise, earth (ordinary ground) two degree rise and finally by vegetation (Grass) one degree rise. Furthermore, Table 10 and Table 11 data respectively shows consistency of rise in 
Table 16. Reasons for displeasure with UHI in the three locations.

\begin{tabular}{|c|c|c|}
\hline S/No & Community & Reasons for Pleasure \\
\hline 1. & Mile 1 Diobu & $\begin{array}{l}\text { - } \quad \text { Disease epidemic (Heat rashes) } \\
\text { - } \quad \text { Poor fish catch resulting from thermal shock on aquatic lives. } \\
\text { - } \quad \text { Suffocation and Death } \\
\text { - High cost of living (frequent use of generator) }\end{array}$ \\
\hline 2. & Rumuomasi & $\begin{array}{l}\text { - } \quad \text { Increased use of generators } \\
\text { - } \quad \text { Noise and air Pollution } \\
\text { - } \quad \text { Suffocation and Death } \\
\text { - High cost of living(frequent use of generator) }\end{array}$ \\
\hline 3. & Old GRA & $\begin{array}{l}\text { - Distortion of original plan, greenery replaced by buildings } \\
\text { - } \quad \text { Discomfort resulting from increased pavements. } \\
\text { - } \quad \text { Higease epidemic as a result of UHL. } \\
\text { High of living (frequent use of generator). }\end{array}$ \\
\hline
\end{tabular}

temperature to confirm the data in Table 9. Generally it was found that asphalt has great effect in increasing urban heat island more, followed by concrete, Earth (ordinary ground) and finally vegetation has the least effect in this regard, increasing urban heat only by one degree rise in temperature as compared to others road and pavements materials. The above assertions could be seen very visibly in the charts in Figures 1-4 of all the road and pavement materials plot of temperature versus the different pavement materials in the three locations respectively.

The effect of urban heat island on the residents in Table 13 shows that the impact of the roads and pavement materials are actually felt by the residents. The overall effect on the people ranges from increase in hotness of the day, $44.6 \%$ respondents agrees, while $34.3 \%$ says it affects the ambient air quality of the area, and other effects such as impairment of air quality, increased ground level ozone, restlessness and sleeplessness occasioned by high temperature at night, increased spending on running of private generators as a result of lack of electricity supplies etc.

\subsection{Conclusion}

Heat re-radiated by urban structures (corridors) road materials and pavement materials (Asphalts) concrete, vegetation (grass) and earth (ordinary ground) play a very significant role in the (UHI) effect. These materials have the effect of increasing the urban heat island. Asphalt has the greatest effect in increasing the urban heat island by four degree rise in temperature, followed by the concrete by three degree rise in temperature, earth (ordinary ground) by two degree rise in temperature and finally vegetation (grass) by one degree rise in temperature. Furthermore, the perceptions of the residents are corroborated as seen in Tables 13-16 respectively. These also attest to the negative effects of the phenomenon, urban heat island on residents of Port Harcourt city.

\subsection{Recommendation}

The research suggests that further research should focus on other aspects of the environment such as Flora and fauna. The impacts of urban heat island on urban residents especially in the study area are enormous as its combined effect with the global change in temperature has exacerbated impact on residents of the city of Port Harcourt. There has been reported cases of heat rashes epidemic, psychological restlessness as a result of excessive heat at night and day and increased ground level ozone. The research recommends the review of the Port Harcourt Master plan or a total urban renewal programme in the city of Port Harcourt to incorporate more greenbelts and open spaces for planting of tree instead of pavements and concreted areas. This will create a conducive environment for work and for living. It will also reduce the effects of (UHI) and ultimately improve the comfort and living conditions of the residents of the city.

\section{References}

[1] Mabojunje, A.L. (1974) Cities and African Development. University Press, Ibadan, 255. 
[2] Paulsen, A. (2000) Satellite-Derived Urban Heat Islands from Three Coastal Cities and the Utilization of Such Data in Urban Climatology. International Journal of Remote Sensing.

[3] Okereke, P. (2008) Climate Change the Scientific Basis; Adapted from IPCC Working Group I, UNEP Report (2007).

[4] Rosenfeld, A.H., Romm, J.J., Akabari, H. and Pomerantz, M. (1998) Communities: Strategies for Heat Island Mitigation and Smog Reduction. Energy and Building, 28, 51-62.

[5] Berkely, L. (2011) National Laboratory, Urban Heat Island Group. Lawrence-Berkeley Laboratory.

[6] Wikipedia (2009) Implications of Temporal Change in Urban Heat Island Intensity Observed at Georgia Stations, Geographical Research Letters, 34, L01175.

[7] Block, A. (2008) National Laboratory. High Temperatures.

[8] Ren, G.N., Chu Z.Y, Chen, Z.H. and Ren, Y.Y. (2007) Implications of Temporal Change in Urban Heat Island Intensity Observed at Beijing and Wuhan Stations. Geophysical Research Letters, 34, Article ID: 105711.

[9] Oluwamno, S. (2006) Intensity and Form of the Urban Heat Island in Barcelona, Adapted from Moreno-Garcia, C.M. Cited in Research Gate, Abstract.

[10] Kalnay, C. (2003) Rapid Urbanization Warming China’s Climate’s Faster than Other Areas. Proceedings of the National Academy of Science.

[11] Winston, T.L. (2011) The Barrow of Urban Heat Island Study: Soil Temperatures and Active Layer Thickness. K.M Hintel University of Cincinnati, Cincinnati.

[12] Deanna, C. (2014) Humid Cities Are Worse than Urban Heat Island than Dry Cities: Earth Sky Org.

[13] Hansen, J., Ruedy, R., Sato, M., Imhoff, M., Lawrence, W. and Easterling, D. (2001) A Closer Look at United States and Global Surface Temperature Change. Journal of Geophysical Research, 106, 23947-23963.

[14] Schaller, S. (2008) Landscapes Representations and the Urban Rural Dichotomy in Empirical Urban Heat Island Literature.

[15] Kalnay, E. and Cai, M. (2008) Impact of Urbanization and Land Use Change on Climate. Nature, 423, 528-531.

[16] Lee, H.-Y. (1993) An Application of NOAA AVHRR Thermal Data to the Study of Urban Heat Island. Atmospheric Environment Part B: Urban Atmosphere, 27, 1-13.

[17] Camilloni, I. and Barros, V. (1997) On the Urban Heat Island Effect Dependence on Temperature Trends. Climate Change, 37, 665-681.

[18] Ren, E.Y. (2008) Urban Climate Change, UCC Research Network Group, Earth Institute Columbia University. uccrn.org.

[19] Geoff, C. (2008) Tornado Warning Preparedness Meteorologist Ontario Region Client Services Environment Canada.

[20] Encyclopedia (2009) Urban Heat Island. National Education Geographic. Com.

[21] Stewart, R. (2011) Member of Research Group on Heat and the City. www.heat and city.org.uk.

[22] Ogionwo, W. (1979) Social Survey of Port Harcourt. Heinemann Educational Publishing Ltd., Ibadan, 350.

[23] Yamane, T. (1967) Statistics: An Introductory Analysis. 2nd Edition, Harper and Row, New York.

[24] National Bureau of Statistics, NBS (1991) Nigerian Population Statistics.

[25] National Population Commission (2012) Census and Base Line Data. Abuja. 